\title{
Bradysia sp. em morangueiro
}

\author{
Bradysia sp. in strawberry
}

\section{Bernadete Radin ${ }^{\mathrm{I}}$ Vera Regina dos Santos Wolff ${ }^{\mathrm{I}}$ Bruno Brito Lisboa ${ }^{\mathrm{I}}$ Sidia Witter José Ricardo Pfeifer Silveira ${ }^{\mathrm{I}}$}

-NOTA-

\section{RESUMO}

No trabalho, relatam-se os primeiros registros de Bradysia sp. (Insecta: Diptera: Sciaridae) em morangueiro (Fragaria $x$ ananassa Duch.), cultivado no Município de Eldorado do Sul, RS. O cultivo foi realizado em sacolas com três metros de comprimento, preenchidas com substrato composto de casca de arroz e turfa, dispostas horizontalmente sobre bancadas de madeira, em ambiente protegido. A presença de Bradysia sp. foi observada na segunda quinzena de agosto de 2005. Neste trabalho, estão descritos os sintomas apresentados no morangueiro pela praga, prováveis conseqüencias sobre o aparecimento de doenças e uma breve descrição morfológica da Bradysia sp., adulto e fase larval.

Palavras-chave: Fragaria x ananassa, "fungus gnats”, praga, ambiente protegido.

\section{ABSTRACT}

This paper describes the first record of Bradysia sp. (Insecta; Diptera; Sciaridae) in strawberry (Fragaria $\mathbf{x}$ ananassa), cultivated in the city of Eldorado do Sul, RS, Brazil. Strawberry was planted in plastic bags filled with a mixture of burnt rice hulls and peat and cultivated in a greenhouse. The presence of Bradysia sp was noticed in the second fortnight of August, 2005. The symptoms in strawberry and the probable consequences in terms of disease arising were described in the present study, as well as the morphological characterization of Bradysia sp. and its illustrations.

Key words: Fragaria x ananassa, "fungus gnats", pest, protected environment.
O morangueiro é cultivado nas mais variadas regiões do mundo. No Brasil, a produção de morango é estimada em 40 mil toneladas anuais, concentrando-se, principalmente, nos Estados de Minas Gerais (41,4\%), Rio Grande do Sul (25,6\%) e São Paulo (15,4\%). Essa cultura é produzida predominantemente, em propriedades familiares, sendo que a maioria possui de 0,5 a 1,0 ha, gera emprego para três pessoas $\mathrm{ha}^{-1}$ ano $^{-1}$, conferindo elevada importância socioeconômica e destaca-se pela alta rentabilidade por área (RESENDE et al., 1999).

O cultivo sucessivo, na mesma área, desencadeia a incidência de doenças tanto da parte aérea como do sistema radicular, constituindo-se em um dos principais problemas da cultura, os quais tendem a se agravar com o decorrer do tempo (ANDRIOLO et al., 2002). Uma das soluções para esse problema é o cultivo com utilização se substrato de plantio ao invés de solo, o que ocorre normalmente em ambientes protegidos. O cultivo em estufa tem crescido, pois proporciona proteção às culturas, principalmente com relação às adversidades climatológicas, como geadas, granizos, chuva, vento e alta intensidade de radiação solar. Além disso, reduz custos com fertilizantes, defensivos e favorece o controle de pragas e doenças. Entretanto, nesse tipo de cultivo ocorre um aumento da temperatura e da umidade relativa do ar, nem sempre desejáveis.

IFundação Estadual de Pesquisa Agropecuária (FEPAGRO). Rua Gonçalves Dias, 570, Bairro Menino Deus, 90130-060, Porto Alegre, RS, Brasil. E-mail: radin@fepagro.rs.gov.br. 
No morangueiro, em cultivos tradicionais, as principais doenças são o mofo-cinzento (Botrytis cinerea), antracnose (Colletotrichum sp.), verticilose (Verticillium sp.), fusariose (Fusarium oxysporium), micosferela (Mycosphaerella fragariae) (FORTES \& COUTO, 2003) e as principais pragas são os ácaros (Tetranychus urticae; Steneotarsonemus pallidus), pulgões (Capitophorus fragaefolii; Cerosipha forbesi), lagartas (Agrotis spp.) e coleópteros (Lobiopa insularis) (SALLES, 2003). Até o momento, não há registro de ocorrência de Bradysia spp. (Diptera: Sciaridae) para a cultura do morangueiro. Esse inseto pode ser uma importante praga em cultivos em estufa (JAMES et al., 1995; DREISTADT, 2001; CLOYD \& ZABORSKI, 2004; LEWANDOWSKI et al., 2004). Segundo CLOYD \& ZABORSKI (2004) e LEWANDOWSKI et al. (2004), o díptero Bradysia spp., conhecido como "fungus gnats", pode ocorrer em diversas partes do mundo se as condições forem favoráveis. Suas larvas alimentam-se, preferencialmente, de matéria orgânica, fungos e raízes e, ocasionalmente, de hastes e folhas (LEATH \& NEWTON, 1969). Por terem uma alimentação diversificada, várias espécies desse gênero têm se tornado praga, causando grandes perdas econômicas.

No Brasil, Bradysia sp. é conhecida como mosca-do-cogumelo e tem causado prejuízos em cogumelos, por se alimentarem das radicelas e tecidos tenros, provocando seu secamento (GALLO et al., 2002). Na cultura da alfafa, quando há intensa alimentação das larvas, pode ocorrer a morte das mudas. No entanto, se a intensidade for menor, essas sobrevivem, mas tornam-se mais suscetíveis ao ataque de doenças como a fusariose (LEATH \& NEWTON, 1969). Portanto, esses insetos podem causar danos diretos, quando se alimentam das raízes das mudas e danos indiretos, quando os adultos disseminam fungos fitopatogênicos entre as plantas, através de esporos aderidos ao seu corpo (KEATES et al., 1989) ou no momento em que as larvas abrem galerias nas raízes predispondo-as à entrada de microorganismos.

Para avaliar as inter-relações entre Bradysia sp. e Phytium sp. em diferentes espécies de plantas cultivadas em estufa, GARDINER et al. (1990) observaram que este inseto é importante na disseminação dessa doença. KALB \& MILLAR (1986) verificaram que Bradysia impatiens (Johannsen, 1912) atuava como vetor de Verticillium albo-atrum Reinke \& Berthold em plantas de alfafa. KEATES et al. (1989) constataram a presença de esporos dos fungos fitopatogênicos Fusarium sp., B. cinerea e Phoma sp. aderidos em larvas e adultos de Bradysia sp. em viveiro de mudas de coníferas. Também foram observados, como vetores de patógenos de solo, o Fusarium oxysporum Sclechtend, em plantas de tomate e feijão (GILLESPIE \& MENZIES, 1993) e ainda como uma praga importante de ornamentais cultivadas em estufa (THOMAS, 2001).

No presente trabalho, os objetivos são registrar a ocorrência de Bradysia sp. no cultivo de morangueiro em estufa, descrever os danos e fazer uma breve descrição morfológica das larvas e dos adultos. As observações foram feitas na cultura do morangueiro cultivada em estufa, coberta com polietileno transparente de baixa densidade, na Fundação Estadual de Pesquisa Agropecuária - FEPAGRO, no Município de Eldorado do Sul, RS (latitude $30^{\circ} 05^{\prime}$ S, longitude $51^{\circ}$ 39' W, altitude de, aproximadamente, $10 \mathrm{~m}$ ), localizado na região ecoclimática da Depressão Central, no período de maio a dezembro de 2005.

O cultivo do morangueiro, cultivar aromas, foi realizado em substrato acondicionado em sacolas plásticas de 3m de comprimento (Figura 1A, 1B), colocadas horizontalmente, em três níveis $(0,40 \mathrm{~m}, 1,20 \mathrm{~m}$ e 1,60m da superfície do solo), sobre uma bancada de madeira. O substrato era composto de $50 \%$ de casca de arroz queimada $+50 \%$ de turfa. A irrigação foi realizada por meio de mangueiras gotejadoras colocadas no interior de cada sacola, mantendo-se a umidade próxima à capacidade de campo.

Na segunda quinzena de agosto, verificouse que algumas plantas apresentavam as folhas mais velhas com as bordas com coloração marrom (Figura 1A) e algumas plantas estavam mortas (1B). No início de setembro, constatou-se a presença de larvas no substrato, nas proximidades e no interior das raízes. Para identificação dessas larvas, foram coletadas, aleatoriamente, dez plantas com sintomas e levadas para o laboratório de entomologia da FEPAGRO. Desse modo, foram identificadas em gênero como Bradysia sp. as larvas, pupas e adultos do inseto, via exame em estereomicroscópio, utilizando-se a descrição de STEFFAN (1966).

Provavelmente, o ambiente rico em matéria orgânica e com elevada umidade foi adequado para o desenvolvimento das larvas. Verificou-se ainda o crescimento de algas nas paredes internas das sacolas, que é uma fonte de alimento para esses insetos nesse estágio de desenvolvimento (KEATES et al., 1989).

Do dia 19/08 ao dia 30/09, ocorreu a morte de $19,5 \%$ das plantas de um total de 168 cultivadas, observando-se, em todas elas, a presença de larvas nas raízes. Em algumas sacolas, a presença de Bradysia sp foi constatada em quase todas as plantas (Figura 1A - linha tracejada), enquanto em outras, dispostas ao lado, (Figura $1 \mathrm{~A}$ - linha contínua) não havia 


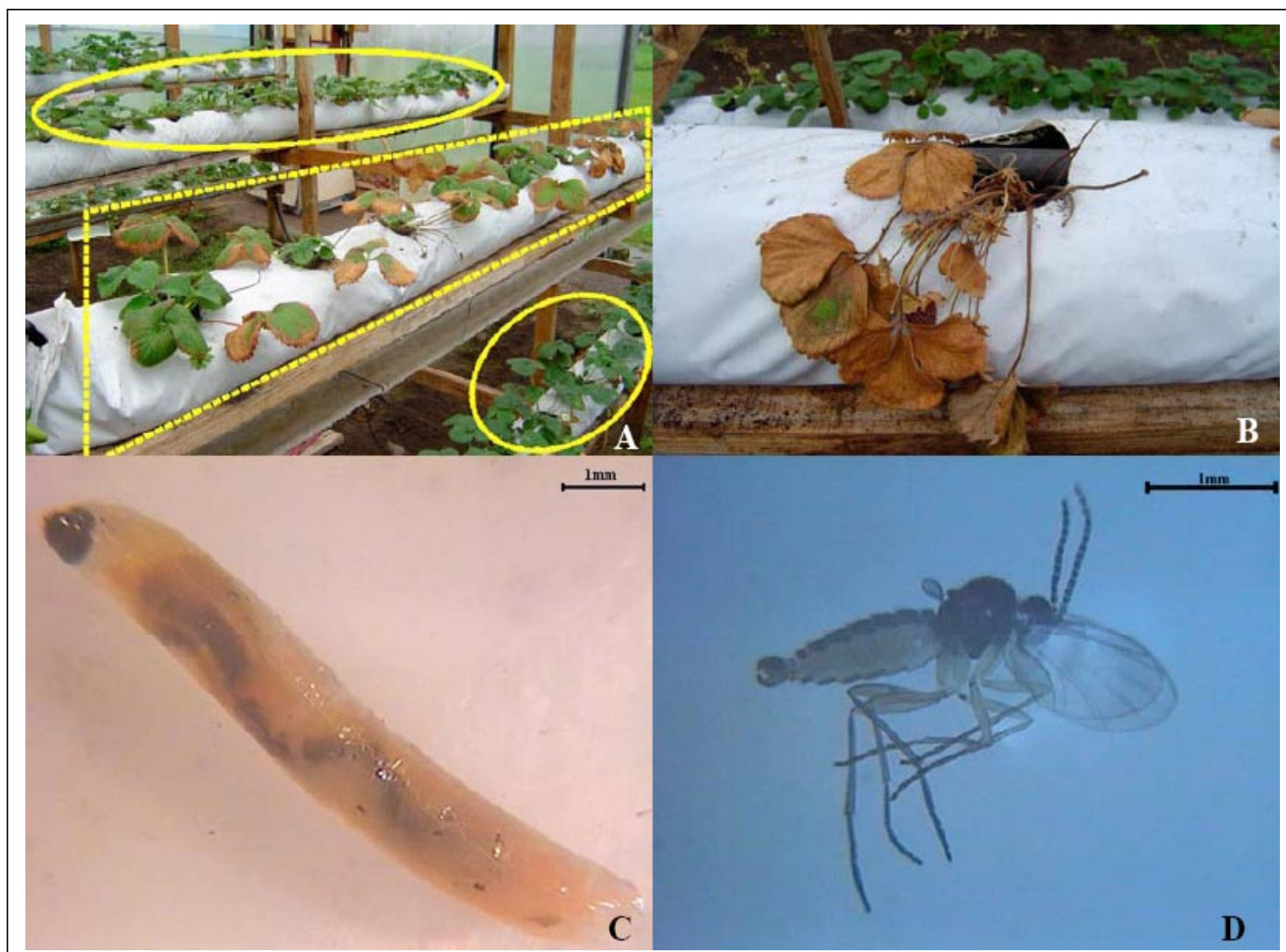

Figura 1 - Sintoma inicial observado em plantas de morangueiro - linha tracejada, sem sintoma - linha contínua (A) e em estágio mais avançado (B). Larva de Bradysia sp. (C) e adulto de Bradysia sp. (D). Eldorado do Sul, RS.

sintomas de ataque, podendo-se inferir que as larvas circulavam pelo substrato dentro da sacola, mas não passavam de uma para outra.

O aumento do número de plantas atacadas por larvas desse inseto coincidiu com a ocorrência da antracnose do rizoma, doença causada pelo fungo Colletotrichum fragariae Brooks, e também dos sintomas do mofo cinzento, causado por Botrytis cinerea Persoon ex Fries. Em relação à antracnose, o patógeno pode penetrar no rizoma de forma direta ou por lesões (TANAKA et al., 1997), condição propiciada pelas larvas de Bradysia sp., ou, se o patógeno estava presente no substrato, as lesões propiciaram o aumento da incidência do patógeno (JARVIS et al., 1993). Já o mofo cinzento, por tratar-se de uma doença da parte aérea do morangueiro, pode ter sua disseminação facilitada para plantas ou áreas adjacentes por adultos de Bradysia sp.

As larvas de Bradysia sp apresentam corpo liso, semitransparente, revelando o conteúdo do trato digestivo e a cabeça preta (Figura 1C). A pupa apresenta corpo branco leitoso. Os adultos possuem corpo de coloração cinza e preto com cerca de $2,5 \mathrm{~mm}$ de comprimento, antenas moniliformes longas, o primeiro par de asas membranosas, o segundo par transformado em halteres, pernas finas e longas (Figura 1D). Esse gênero pode ser distinguido de outros gêneros norteamericanos pela combinação das características do palpo maxilar tri-articulado, metatíbia com dois espinhos subiguais e asas posteriores com veias nuas encontradas nos adultos (STEFFAN, 1966), sendo esses caracteres observados nos exemplares analisados.

O sistema de cultivo do morangueiro, em vasos ou sacolas, com o uso de substrato é recente e pode ser a razão de esse inseto não ter sido constatado anteriormente. Por meio das observações realizadas, infere-se que Bradysia sp. pode constituir-se em uma importante praga e atuar como disseminadora de microorganismos fitopatogênicos, quando o cultivo ocorrer em substratos ricos em matéria orgânica e com elevada umidade.

\section{AGRADECIMENTOS}

Os autores agradecem o apoio financeiro recebido pelo Conselho Nacional de Desenvolvimento Científico e Tecnológico (CNPq), processo $\mathrm{n}^{\circ}$ 476839/2003-03.

Ciência Rural, v.39, n.2, mar-abr, 2009. 


\section{REFERÊNCIAS}

ANDRIOLO, J.L. et al. Acumulação de matéria seca e rendimento de frutos de morangueiro cultivado em substrato com diferentes soluções nutritivas. Horticultura Brasileira, v.20, n.1, p.24-27, 2002.

CLOYD, R.A.; ZABORSKI, E.R. Fungus Gnats, Bradysia spp. (Diptera: Sciaridae), and other arthropods in commercial bagged soilless growing media and rooted plant plugs. Journal of Economic Entomology, v.97, n.2, p.503-510, 2004.

DREISTADT, S.H. Fungus gnats, shore flies, toth flies, and march flies. Pest note, Davis, 2001. Capturado em 04set.2007. Online. Disponível na internet http://www.ipm.ucdavis.edu/ pdf/pestnotes/pnfungusgnats.pdf

FORTES, J.F.; COUTO, M.E. Doenças fúngicas e bacterianas. In: FORTES, J.F.; OSÓRIO, V.A. (Ed.). Morango fitossanidade. Informação Tecnológica. Brasília: Embrapa, 2003. 36p. p.11-18.

GALLO, D. et al. Entomologia agrícola. Piracicaba: FEALQ, 2002. 920p.

GARDINER, R.B. et al. Ingestion of Phytium spp. by larvae of the fungus gnat Bradysia impatiens (Diptera:Sciaridae). Annals of Applied Biology, v.116, p.205-212, 1990.

GILLESPIE, D.R.; MENZIES, J.G. Fungus gnats vector Fusarium oxysporum f. sp. radicis-lycopersici. Annals of Applied Biology, v.123, n.3, p.539-544,1993.

JAMES, R.L. et al. Botrytis cinerea Carried by Adult Fungus Gnats (Diptera: Sciaridae) in container nurseries . Tree Planters' Notes, v.46, n.2, p.48-53,1995.

JARVIS, W.R. et al. Transmission of Pythium apanidermatum to greenhouse cucumber by fungus gnats Bradysia impatiens
(Diptera: Sciaridae). Annals of Applied Biology, v.122, n.1, p.23-29,1993.

KALB, D.W.; MILLAR, R.L. Dispersal of Verticillium alboatrum by the fungus gnat (Bradysia impatiens). Plant Disease, v.70, p.752-753, 1986.

KEATES S.E. et al. Populations of adult fungus gnats and shore flies in British Columbia container nurseries as related to nursery environment, and incidence of fungi on the insects. New forests, n.3, p.1-9, 1989.

LEATH, K.T.; NEWTON, R.C. Interaction of a fungus gnat, Bradysia sp. with Fusarium spp . on alfalfa and red clover. Phytopathology, v.59, p.257-258, 1969.

LEWANDOWSKI, M. et al. Biology and morphometry of Lycoriella ingenua (Diptera: Sciaridae). Biological Letters, v.41, n.1, p.41-50, 2004. Capturado em mar.2006. Online. Disponível http://www.biollett.amu.edu.pl/biollett_41_1_6.pdf.

RESENDE, L.M.A. et al. Panorama da produção e comercialização do morango. Informe agropecuário, v.20, n.198, p.5-19, 1999.

SALLES, L.A.B. Pragas. In: FORTES, J.F.; OSÓRIO, V.A. (Ed). Morango fitossanidade. Informação tecnológica. Brasília: Embrapa, 2003. 36p. p.23-28

STEFFAN, W.A. A Generic revision of the family Sciaridae (Diptera) of America North of Mexico. University of California Publications in Entomology. v.44, p.1-77, 1966.

TANAKA, M.A.S. et al. Doenças do morangueiro (Fragaria $\mathbf{X}$ ananassa Duch.). In: KIMATI et al. Manual de fitopatologia - doenças de plantas cultivadas. 3.ed. São Paulo: Agronômica Ceres, 1997. p.556-571.

THOMAS, C. Strategies for managing fungus gnats in greenhouse and nursery production. Regulatory horticulture, v.27, p.1319, 2001. 